\title{
Optimization Of Raw Material Inventory Costs In The Food Supply Chain Using Differential Evolution Algorithm
}

\author{
Mara Huriga Priymasiwi ${ }^{1, *}$, Mustafid ${ }^{2}$ \\ ${ }^{1}$ Magister Program of Information System, School of Postgraduate Studies, Diponegoro University, Semarang - \\ Indonesia \\ ${ }^{2}$ Department of Mathematic, Faculty of Science and Mathematic, Diponegoro University, Semarang - Indonesia
}

\begin{abstract}
The management of raw material inventory is used to overcome the problems occuring especially in the food industry to achieve effectiveness, timeliness, and high service levels which are contrary to the problem of effectiveness and cost efficiency. The inventory control system is built to achieve the optimization of raw material inventory cost in the supply chain in food industry. This research represents Differential Evolution (DE) algorithm as optimization method by minimizing total inventory based on amount of raw material requirement, purchasing cost, saefty stock and reorder time. With the population size, the parameters of mutation control, crossover parameters and the number of iterations respectively $80,0.8,0.5,200$. With the amount of safety stock at the company 7213.95 obtained a total inventory cost decrease of $39.95 \%$. Result indicate that the use of DE algorithm help providein efficient amount, time and cost.
\end{abstract}

Keywords: Differential evolution algorithm, inventory optimization, raw materials optimization, food supply chain

\section{Introduction}

The inventory management of raw materials used to tackle problems occurred particularly in the food industry to achieve effectiveness, timeliness and service levels high. In the management of supplies, the costs become inseparable factors in the process of preparation. The function of inventory management is to control inventory from start up to purchase stock warehouse. Supply chain management is one of the inventory management of forms where companies need to set when the purchase was done and pressed costs incurred [1]. In the process of supply chain in particular the food industry there is a charge on the flow of supply include the cost of purchasing, booking fees, costs of transport and storage costs [2].

On the supply chain, part of the purchasing company on duty to determine when the purchase of raw materials is carried out, how many purchases are seen from the number of orders by optimization method, namely, genetic algorithm and algorithm differential evolution. The algorithm is a method of DE lot sizing which is used to calculate the number of order and order period with the aim of achieving optimal cost and achieve efficiency of enterprise [3]. The principle is based on analogies with evolutionary process initialization, the process of mutation, crossover and process selection process [4]. Advantages of the algorithm DE that is structured in a simple, easy to implement, fast reaching a solution and are tough (has a small standard deviation).
The raw material is something that is used to produce a product [5]. The availability of raw materials affect the production process so as to affect the income of an enterprise. A large number of reservations made not only by a single consumer makes the company should be able to manage the inventory of raw materials so that the absence of a shortage when the production process is underway [6]. Therefore, with the availability of raw materials in the production company will help companies in conducting production processes in accordance with the requests and wishes of the consumer.

Inventories raw materials become fundamental in food companies, because the dynamic demand and availability of raw materials can cause problems over costs incurred. The DE algorithm can be used as a method of solving problems on the optimization of the cost of supply of the raw material. This algorithm works to suppress the cost of inventory preparation costs resulting in optimal inventory cost using computer based [7]. The use of computer based systems can improve the company's performance because it can automate and compute quickly, so that it can be used to predict production needs [7].

Inventory cost optimization is necessary given the high price of supplies, a large number of requests and the need for raw materials that need to be provided. This research will be discussed about the supplies of raw materials in food industry companies that produce food products.

* Corresponding author: priymasiwi.marahuriga@gmail.com 
This research aim is applying differential evolution algorithm for the optimization of the total cost of supplies of raw materials in the supply chain the food industry based on the number of requests, time of booking, purchase costs and stock available, as well as an inventory control system for the food industry.

\section{Differential Evolution Algorithm}

The Differential Evolution (DE) Algorithm is an efficient global optimization algorithm based on principle of evolution [8]. DE algorithm is the development of gemetic algorithm that is solution search technique through mutation operation process, crossover and selection [4]. Just like any other evolutionary algorithm, $\mathrm{DE}$ uses the individual as a candidate solution representation. The difference between the DE algorithm is in the self adaptive mutaion scheme and the process selection where all solutions in DE have the same chance of being selected as the parent (the target vector). Each individual is defined as a dimensionless vector- $n(X € R n)$. With dimensions-n as global optimization i.e :

$$
\begin{aligned}
& \min _{\mathbf{x} \in X \subset \mathbb{R}^{n}} C(\mathbf{x}) . \\
& \mathrm{C}(\mathrm{x})=\sum_{t=1}^{T}\left(K^{R} \gamma_{t}^{R}+K^{M} \gamma_{t}^{M}+h^{R} Y_{t}^{R}+h^{M} Y_{t}^{M}\right)
\end{aligned}
$$

where

$$
\boldsymbol{\gamma}_{t}^{R}=\left\{\begin{array}{l}
\mathbf{1}, \text { jika } \boldsymbol{Z}_{t}^{\boldsymbol{R}}>0, \\
\mathbf{0}, \text { lainnya }
\end{array} \quad \boldsymbol{\gamma}_{t}^{\boldsymbol{M}}=\left\{\begin{array}{l}
\mathbf{1}, \text { jika } \boldsymbol{Z}_{t}^{\boldsymbol{M}}>0, \\
\mathbf{0}, \text { lainnya }
\end{array}\right.\right.
$$

The description shown in $t$ is the time time period, $\mathrm{t}=1,2,3 \ldots \mathrm{T} ; \mathrm{hR}$ is a holding cost for complementary raw materials per unit of time; $\mathrm{hM}$ is holding cost for the main raw material per unit of time; $Z_{t}^{R}$ is a number of complementary raw material needed to be produced in $\mathrm{t}$ period; $Z_{t}^{M}$ is a number of main raw material needed to be produced in t period; $K^{R}$ setup cost complementary raw materail; $K^{M}$ setup cost main raw material; $Y_{t}^{R}$ safety stock of complementary raw material in t period; $Y_{t}^{M}$ safety stock main raw material in $\mathrm{t}$ period and $\gamma_{t}^{R}$ number of complementary raw material needs to be purchased in $\mathrm{t}$ period and $\gamma_{t}^{M}$ number of main raw material needs to be purchased in $t$ period. Individuals are members of the population in individuals to $\mathrm{N}$ denoted as :

$$
\mathrm{S}=\left\{\mathrm{X}_{1}, \mathrm{X}_{2}, \ldots ., \mathrm{X}_{\mathrm{N}}\right\}
$$

The number of poplations at the $\mathrm{N}$ value specified in a search range includes :

$$
\begin{aligned}
& X \subset \mathbb{R}^{n}, \\
& \mathbf{x}_{i}=\left(x_{i 1}, x_{i 2}, \ldots, x_{i n}\right)^{\top} \in X, \quad i \in I=\{1,2, \ldots, N\}
\end{aligned}
$$

The value of $i$ is a notation describing a period or time. X shows a variable of raw material sought. [8].

\section{Mutation}

Individuals who do not act as target individuals will experience mutations. Some mutation processes are formulated as follows :

$$
\operatorname{vi}(\mathrm{t}+1)=\mathrm{xr}_{1}(\mathrm{t})+\mathrm{F}\left(\mathrm{xr}_{2}(\mathrm{t})-\mathrm{xr}_{3}(\mathrm{t})\right)
$$

where vi is a mutant vector resulting from the mutation done, $t$ is the number of iterations, $F €(0,1)$ is the parameter used, $g$ defines as the best individual index in the formulated population:

$$
\mathrm{g}=\arg \min _{j \in I} C\left(X_{j}\right)
$$

$\mathrm{rk} \in \mathrm{I}, \mathrm{k}=1,2,3 \ldots, 5$; Rabdom selection is done by index i. The carrier mutation being the parameter is $\mathrm{N}>5$

\section{Recombination}

After mutation, the next step is recombination is applied on the generated vector vi, producing a trial vector Ui.

$$
\mathrm{U}_{\mathrm{i}}=\left(\mathrm{u}_{\mathrm{i} 1}, \mathrm{u}_{\mathrm{i} 2}, \ldots . \mathrm{u}_{\mathrm{in}}\right)
$$

where

$$
u_{i j}(t+1)=\left\{\begin{array}{cc}
v_{i j}(t+1)_{i f ~} \leq C R \text { or } j=R I(j) \\
x_{i j}(t) & \text { lainnya }
\end{array}\right.
$$

$\mathrm{R}$ random variable on range $[0,1]$; $\mathrm{CR} \in[0,1]$ crossover constant; RI(i) index random from $\{1,2, \ldots n\}$. The difference in value of $R$ is used for every $i$ and $j$, whilemthe use of RI(i) guarantees that at least one of the components of the mutated vector vi inherited to the trial vector ui. $I=(1,2, \ldots N)$ is a population period, and $j=(1$, $2, \ldots, n) \in I$ is a period on $I$ and $i=(1,2, \ldots, n)) \in I$ is a period on $\mathrm{I}$ then $\mathrm{j} \leq \mathrm{i}$.

\section{Selection}

Finaly, the last step is selection. Vector $u i$ is compared against the original individuals xi and the best between them is included in the population of the next generation

$$
x_{i}(t+1)=\left\{\begin{array}{cc}
u_{i(t+1)} & \text { if } C\left(u_{i}(t+1)\right)<C\left(x_{i}(t)\right) \\
x_{i(t)} & \text { lainya },
\end{array}\right.
$$

The new population iteratively undergoes the same procedure as above, until user-defined stopping criterian is fulfilled..

\section{Methods}

The research was conducted on food companies that produce food spices that will be sold to food processing companies such as instant food or packaged foods. The resulting spice product has the main and complementary raw material arrangement. So it can be known the umber of raw materials needed per $\mathrm{kg}$ of spice products produced. Customers alse place orders based on a period 
of time in which a period of is 6 months. From the number of customerborders and there is a period of time, the company must be able to manage and plan the amount of raw material inventory, the costs of raw material inventory, storage costs required and when ordering purchased of raw material done. The order from customers starting with the initial order was followed by a contract agreement number and the price of spices that will be ordered for a period (6 months). After that, do a reorder followed by seasoning delivery date on request every month.

As for the inventory level is divided into two, among others, the amount of crude raw material supplies and the amount of supplies of raw materials and a half so that although manufactured again. Once known the amount of inventory or safety stock levels, then performed a calculation of how much crude the raw materials will be purchased and when done re-ordering by finding the value of ROP. Optimization of raw materials is carried out on the basis of the costs that are used include the cost of purchase, purchase, storage costs, the amount of the available raw materials (safety stock) so from the trio produced a value of raw material inventory optimization model and algorithm of using DE.

The study begins by determining the themes and objectives of the problem as the procedure of planning research based on problems occurred, namely supplies of raw materials in food companies, further study of literature as the Foundation research. The study of the literature undertaken related to the supply chain companies of the food industry and the algorithm DE. Identification and formulation of the problem as the second stage is done by performing an investigation on variable supplies of raw materials. This variable is the basis for building material supply system bakupada the optimal food industry.

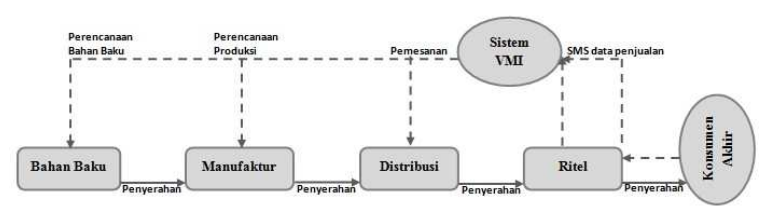

Fig. 1 Raw Material Inventory Model

The required of primary data in the form of a booking, purchase of raw materials data and data stock of supplies of raw materials in food companies in the period July to December 2016. Inventory Data using the calculation of Safety Stock and Reorder Point to get an estimate of the amount of stock a safe and minimum population estimate for stock purchases done again. Whereas the calculation of the cost of inventories obtained from data of purchase using Differential Evolution Algorithm for result optimal purchase total cost.

\section{Result and Discussion}

Research results in the form of raw material inventory system information in the form of supplies of raw materials and the use of algorithms for minimizing the cost of DE supplies. Supply chain inventory model illustrated in Figure 2.

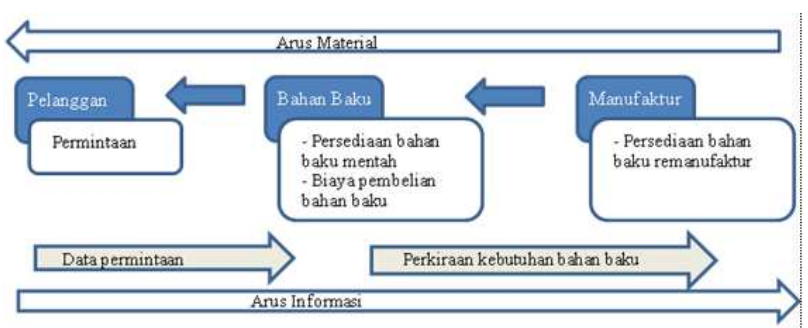

Fig. 2. Supply chain inventory model

\subsection{Result of Inventory Cost}

An estimate of the production needs of the customer or sales request amount and calculation of the raw materials needed to manufacture a product with the amount of supplies.

Table 1. Total Production Needs

\begin{tabular}{|l|c|c|c|c|}
\hline Month & QCE & QDE & QDB & QDL \\
\hline Jul-16 & 10 & 0 & 0 & 5 \\
\hline Agust-16 & 40 & 40 & 30 & 13 \\
\hline Sep-16 & 0 & 50 & 0 & 18 \\
\hline Okt-16 & 15 & 0 & 0 & 0 \\
\hline Nop-16 & 30 & 50 & 28 & 14 \\
\hline Des-16 & 60 & 55 & 30 & 16 \\
\hline
\end{tabular}

To calculate the magnitude of the costs of inventory, required the calculation of storage costs and the cost of the purchase. For both these costs, required safety stock calculation and ROP to squeeze costs by taking inventory of the storage of raw materials at warehouses in order to avoid the price increase of raw materials that may occur.

Calculation of the safety stock depends on the number of requests (purchase order), the standard deviation request and service level. The value of standard deviation is sought by collecting data requests in a period of 6 months. The value of the standard deviation will be updated every month in accordance with the data input requests. Service level is anticipation supplies raw materials to keep it from happening stock out with looking at the level of service inventory that is $95 \%$ on normal distribution table. Safety stock is the amount of inventory a safe raw materials which can be known by calculating the standard deviation request based on request data 6 last monitored then multiplying the results of standard deviation request is generated with service level inventory at the warehouse. Obtained results of standard deviation requirements 770.23 with an average demand of the results the approximate year of 2016 needs $1,700.50 \mathrm{Kg}$ per month. The results of the calculation of the standard deviation obtained lead time of 13 with an average of 65 days lead time. But the lead time is used in the calculation of the safety stock is 52 days (lower limit lead time) with the consideration that this number is safe enough in tackling the level uncertainty lead time to high supplier. Based on the above data obtained a safety stock of 7213.Kg. 
Updates number of products is often embodied in the form of the value of the reorder point. ROP was determined based on 3 variables i.e. lead time (LT), the level of demand during lead time (d), and the safety stock. The value of lead time in the waiting time can be of use for the purposes of stock renewal period of demand that occurs, the level of order is calculated from the average value of customer demand over a period of 6 months and the amount of stock to be safe. ROP shows the number of the remaining raw materials where the raw materials in the warehouse must be updated immediately because the amount of safety stock that has reached the minimum threshold. The ROP values will always be updated according to the changes in sales that occur every month. Determination of the reorder point is obtained by summing the need for safety stock company with lead time. The value of lead time 78, the need for lead time (d), namely $132,639.29 \mathrm{~kg}$ and safety stock $137.76 \mathrm{~kg}$. Calculation based on reorder points results were obtained at the time of the stock in the warehouse of a number of $170,134.77 \mathrm{~kg}$, which means that the reservation is made every time a stock of raw materials was at its 170 tons. The current capacity of the warehouse with the area of $1,104 \mathrm{~m} 2$ capable of accommodating as many as 1,149 tonnes of raw materials assuming all polygons are used to hold raw materials.

The costs taken into account in the cost of inventories comprises costs of purchase and storage costs. Purchase costs consist of the costs of purchase of raw materials, cost of the message and transport costs. The cost of the store has several components manifested in $\mathrm{k}$ as the cost of the damage and the loss of $1 \%$ of the purchase price, as the cost of inventory handling p sebsar $0.5 \%$ of the purchase price, $\mathrm{f}$ as the cost of storage facilities in the amount of $0.5 \%$ of the purchase price. So the total cost of the inventory can be seen from table 2 .

Table 2. Total Inventory Cost

\begin{tabular}{|c|c|c|c|c|}
\hline Material & Number & Setup cost & $\begin{array}{c}\text { Holding } \\
\text { cost }\end{array}$ & Total \\
\hline Pepper & 124 & 17117400 & 334800 & 17452200 \\
\hline $\begin{array}{c}\text { Black } \\
\text { pepper }\end{array}$ & 156 & 19117200 & 374400 & 19491600 \\
\hline Red chili & 52.8 & 1489872 & 25344 & 1515216 \\
\hline Rice & 66 & 876600 & 13200 & 889800 \\
\hline White chili & 35.2 & 921040 & 14080 & 935120 \\
\hline $\begin{array}{c}\text { Cast } \\
\text { pepper }\end{array}$ & 31 & 2088600 & 37200 & 2125800 \\
\hline $\begin{array}{c}\text { Cast black } \\
\text { pepper }\end{array}$ & 39 & 2179500 & 39000 & 2218500 \\
\hline \multicolumn{4}{|c|}{ TOTAL COST } & 44628236 \\
\hline
\end{tabular}

\subsection{Result of Differential Evolution Algorithm}

The cost of the inventory of the company's ongoing need for optimization using calculation in Equation 3:

$\operatorname{Min} \mathrm{C}(\mathrm{x})=\sum_{t=1}^{T}\left(K^{R} \gamma_{t}^{R}+K^{M} \gamma_{t}^{M}+h^{R} Y_{t}^{R}+h^{M} Y_{t}^{M}\right)$

Then converted into :

$$
\operatorname{Min} C(x)=X_{1}+X_{2}+X_{3}+X_{4}
$$

$\mathrm{X}_{1}$ shows the setup cost of raw materials complement, $\mathrm{X}_{2}$ shows the setup cost of the main raw material, $X_{3}$ shows the total holding costs of raw materials and $\mathrm{X}_{4}$ shows the total holding cost of the main raw material.

Optimization calculation of the cost of supply of the raw materials obtained using the algorithm DE. D is the decision variables that add up to 4 there are $X_{1}-X_{4}$. NP is the value of a population totalling 4 i.e. the target individual. Individual 1 individual 2 QCE, i.e. i.e. QDE, individual 3 i.e. QDB, individual 4 i.e. QDL. The values are presented in the following table is 3 initialization for search optimization algorithm on DE.

Table 3. Initial

\begin{tabular}{|c|c|c|c|c|}
\hline & QCE & QDE & QDL & QDB \\
\hline $\mathrm{X}_{1}$ & 2200000 & 2100000 & 900000 & 0 \\
\hline $\mathrm{X}_{2}$ & 20000000 & 18000000 & 1500000 & 900000 \\
\hline $\mathrm{X}_{3}$ & 700000 & 400000 & 200000 & 0 \\
\hline $\mathrm{X}_{4}$ & 3100000 & 9900000 & 1000000 & 100000 \\
\hline $\mathrm{C}(\mathrm{X})$ & 26000000 & 30300000 & 3700000 & 1000000 \\
\hline
\end{tabular}

The above data were shared by 10 million to produce data on the range [0.2] as shown in table 3 .

Table 3. Initial $\mathrm{D}=4 \mathrm{NP}=4$ (continued)

\begin{tabular}{|l|c|c|c|c|}
\hline & Individu 1 & Individu 2 & Individu 3 & Individu 4 \\
\hline $\mathrm{X}_{1}$ & 0,22 & 0,21 & 0,09 & 0,00 \\
\hline $\mathrm{X}_{2}$ & 2,00 & 1,80 & 0,15 & 0,09 \\
\hline $\mathrm{X}_{3}$ & 0,07 & 0,04 & 0,02 & 0,00 \\
\hline $\mathrm{X}_{4}$ & 0,31 & 0,99 & 0,10 & 0,01 \\
\hline $\mathrm{C}(\mathrm{X})$ & 2,60 & 3,03 & 0,37 & 0,10 \\
\hline
\end{tabular}

At this stage, was determined among other parameters $\mathrm{F}$ $=0,8, \mathrm{CR}=0,5$. As well as determining the individuals that will be used to perform the calculation process in advance. For the value of the specified value - randomly.

\section{Mutation}

On the simulation calculation, was determined "individual 1" as the target of the search or the new generation called also the target vector. So that the selected individual value 3 random or random i.e. individual 2, individual 3 and individual 4 The calculation of these mutations using equations of DE (2). Individual 2 and 3 individual deductible first which then generate the difference vector. The value of the difference vector is multiplied by the value $F(0.8)$ yields a value of weighted difference vector as shown in table 4 . Value weighted difference vector then the summation is done with 4 individual noisy generating random vector as described in table 4.

Table 4. Mutation Process 
Table 4. Mutation Process (continued)

\begin{tabular}{|c|c|c|c|c|c|c|c|c|}
\hline & $\begin{array}{c}\text { Indivi } \\
\text { du } 2\end{array}$ & & $\begin{array}{l}\text { Indivi } \\
\text { du } 3\end{array}$ & & $\begin{array}{c}\text { Differen } \\
\text { ce } \\
\text { vector }\end{array}$ & \multicolumn{3}{|c|}{\begin{tabular}{c|c} 
& Weight \\
ed \\
differen \\
ce \\
vector \\
\end{tabular}} \\
\hline $\mathrm{X}_{1}$ & 0,21 & & 0,09 & & 0,12 & & 0,09 \\
\hline $\mathrm{X}_{2}{ }^{\mathrm{x}}$ & 1,80 & - & 0,15 & (= & \multicolumn{2}{|l|}{1,65} & $\mathrm{xF}$ & 1,32 \\
\hline $\mathrm{X}_{3}{ }^{\mathrm{x}}$ & 0,04 & & 0,02 & & 0,02 & \multicolumn{2}{|c|}{$\begin{array}{c}\mathrm{F}=0, \\
80\end{array}$} & 0,01 \\
\hline $\mathrm{X}_{4}{ }^{\mathrm{x}}$ & 0,99 & & 0,10 & & 0,89 & & & 0,71 \\
\hline & \multicolumn{2}{|c|}{$\begin{array}{c}\text { Weighted } \\
\text { difference } \\
\text { vector } \\
\end{array}$} & & \multicolumn{2}{|c|}{ Individu 4} & \multicolumn{3}{|c|}{$\begin{array}{l}\text { Noisy } \\
\text { Random } \\
\text { Vector }\end{array}$} \\
\hline $\mathrm{X}_{1}$ & \multicolumn{2}{|c|}{0,09} & & \multicolumn{2}{|r|}{0} & \multicolumn{3}{|c|}{0,09} \\
\hline $\mathrm{X}_{2}$ & \multicolumn{2}{|c|}{1,32} & $(+)$ & \multicolumn{2}{|c|}{0,09} & $(=)$ & \multicolumn{2}{|c|}{1,41} \\
\hline $\mathrm{X}_{3}$ & \multicolumn{2}{|c|}{0,01} & & \multicolumn{2}{|c|}{0} & & \multicolumn{2}{|c|}{0,01} \\
\hline $\mathrm{X}_{4}$ & \multicolumn{2}{|c|}{0,71} & & \multicolumn{2}{|c|}{0,013} & & \multicolumn{2}{|c|}{0,72} \\
\hline
\end{tabular}

\section{Recombination}

At this stage of recombination, specify a value of CR (crossover) that will be used to determine the trial vector (ui). The value of CR have been determined, namely 0.5 . At this stage the target vector which is individual 1 do crossovers with noisy random vector. When random values greater than the value in the $\mathrm{CR}$ then copy the target vector but if not, copy and insert the values from noisy random vector. So the obtained value of the trial vector (ui).

Table 5. Recombination Process

\begin{tabular}{|c|c|c|c|c|c|}
\hline & $\begin{array}{c}\text { Targe } \\
\mathrm{t} \\
\text { vecto } \\
\mathrm{r}\end{array}$ & $\begin{array}{c}\text { Noisy } \\
\text { Rando } \\
\mathrm{m} \\
\text { Vector }\end{array}$ & & $\begin{array}{c}\text { Trial } \\
\text { vector }\end{array}$ \\
\hline $\mathrm{X}_{1}$ & 0,22 & & 0,09 & & 0,22 \\
\hline $\mathrm{X}_{2}$ & 2,00 & $\begin{array}{c}\mathrm{CR}=0,5 \\
0\end{array}$ & 1,41 & $(=)$ & 1,41 \\
\hline $\mathrm{X}_{3}$ & 0,07 & & 0,01 & & 0,07 \\
\hline $\mathrm{X}_{4}$ & 0,31 & & 0,72 & & 0,72 \\
\hline $\mathrm{C}(\mathrm{X})$ & 2,60 & & 2,24 & & 2,42 \\
\hline
\end{tabular}

\section{Selection}

At the stage of selection that is the stage where do benchmarking between the trial vector with the target vector. The smallest value that will be the new generation.

Table 6. Selection Result

\begin{tabular}{|c|c|c|c|}
\hline & Trial Vector & Target Vector & $\begin{array}{c}\text { New } \\
\text { Generation }\end{array}$ \\
\hline $\mathrm{X}_{1}$ & 0.25 & 0.41 & 0.34 \\
\hline $\mathrm{X}_{2}$ & 1.03 & 3.15 & 0.87 \\
\hline $\mathrm{X}_{3}$ & 0 & 0.01 & 0.01 \\
\hline
\end{tabular}

\begin{tabular}{|c|c|c|c|}
\hline $\mathrm{X}_{4}$ & 0.01 & 0.04 & 0.01 \\
\hline $\mathrm{C}(\mathrm{X})$ & 1.29 & 3.61 & 1.22 \\
\hline
\end{tabular}

From the above calculation, exposure obtained the value of the new generation of each individual and converted back into real value by multiplying the 10 million. So the optimal cost-value obtained supplies of raw materials such as in Table 7 . The optimal cost supply of raw materials.

Table 7. Optimal Cost of Raw Material Inventory

\begin{tabular}{|c|c|c|c|c|}
\hline Product & QCE & QDE & QDB & QDL \\
\hline $\mathrm{X}_{1}$ & 2500000 & 4100000 & 3400000 & 0 \\
\hline $\mathrm{X}_{2}$ & 10300000 & 31500000 & 8700000 & 24500000 \\
\hline $\mathrm{X}_{3}$ & 0 & 100000 & 100000 & 0 \\
\hline $\mathrm{X}_{4}$ & 100000 & 400000 & 100000 & 400000 \\
\hline $\mathrm{C}(\mathrm{X})$ & 12900000 & 36100000 & 12300000 & 26100000 \\
\hline
\end{tabular}

The table above shows the calculation of the cost of inventories using the algorithm $\mathrm{DE}$ for each of the main raw materials and auxiliaries of a product. Generate total cost of inventories amounting to Rp. 26,787,365,--

\section{Conclusion}

. The results of the research shows that the application of differential evolution algorithm in the supply chain of food industry is obtained the optimal inventory cost. With the cross-parameter size, the number of iterations in a row of $80,0.8,0.5,2000$ can suppress the decrease in cost from Rp. 44.608 .636 to Rp. 26.787 .365 ,- or $39,95 \%$.

\section{References}

1 A.D. Sabila, Mustafid, S. Suryono, E3S web of Conference 31, 11015, 2018.

2. Mustafid, A.S. Karimariza, F. Jie, Int. Journal of Agile System and Management, vol. I, no. 11, pp. 1-22, 2018.

3. T. Schulz, International Journal of Production Research, vol. 49, no. 9, pp. 2515-2533, 2011.

4. D. Karaboga and S. Okdem, Differential Evolution Algorithm, TurkJ. Elec. Engin vol 12 no 1, p. 53, 2004.

5. D. Rad, International Journal of Production Economics, vol. 153, pp. 295-308, 2014.

6. S. Pazhani, J. ventur, A. Mendoza, Aplied Mathematical Modelling, vol. I, no. 40, pp. 612-634, 2016.

7. S. Suryono, J.E. Suseno, C. Mashuri, A.D. Sabila, J.A.M. Nugraha, M.H. Priymasiwi, American Scientific Publisher, 2017, Vol.23, 2398-2400

8. K. Price, in An Introduction to Differential Evolution. from New Ideas in Optimization, Mc Graw-Hill, UK, D. Corne, M.Dorigo, 1999, pp. 79-108. 